\title{
Conceptual Model Development of Big Data Analytics Implementation Assessment Effect on Decision-Making
}

\author{
Cecilia Adrian*, Rusli Abdullah, Rodziah Atan, Yusmadi Yah Jusoh \\ Faculty of Computer Science and Information Technology, Universiti Putra Malaysia, 43400 UPM \\ Serdang (Malaysia)
}

Received 12 November 2017 | Accepted 14 February 2018 | Published 5 March 2018

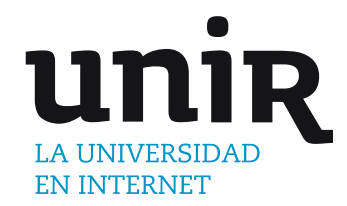

ABSTRACT

\section{KEYWORDS}

Big Data, Data Analysis, Decision-Level, DSS, E-assessment.

DOI: $10.9781 /$ ijimai.2018.03.001

The significance of big data advancement has benefited various organizations to leverage the potential insights and capabilities of big data in organizational performance and decision-making. However, the analytics outcome and quality of big data analytics (BDA) implementation has yet to be addressed. Therefore the aims of this paper are to identify and analyze the affecting factors and elements of BDA implementation and to propose a conceptual model for effective decision-making through BDA implementation assessment. The model is developed based on three dimensions such as performing data strategy (organization), collaborative knowledge worker (people) and executing data analytics (technology). The findings of this ongoing study proceeds with designing a proposed conceptual model with the research hypothesis and may provide a better assessment model for effective decision-making in the long run.

\section{INTRODUCTION}

$\mathrm{M}$ ANY organizations have shifted to data-driven decision-making as a result of the advancements of big data benefits. The use of analytics in real-time decision-making has significant impacts on business activities and performance enhancement [1]. Most of them have benefited from big data analytics (BDA) implementation in many ways, such as information technology (IT) infrastructure, operational, managerial, strategic and organization benefits [2] [3]. The IT infrastructure benefits including using sharable and reusable IT resources that reduce operation cost for IT management and increased IT infrastructure capability. Indirectly, it helps to improve the operational activities by reducing information process cycle time, productivity and quality improvement [2]. Likewise, the analytics results used by business leaders have improved decisionmaking and facilitate better planning in business management activities. BDA implementation will also benefit in strategic long-term planning to support business growth and business value creation that leads to organizational performance enhancement [3][4].

Big data analytics implementation includes processes of managing the big data analytics capabilities and resources (such as technologies, people and analytics processes) [5], and transforming big data into valuable and understandable information [3] by using the analytics applications to gain insights for effective decision-making and enhance the organizational performance [6] [7]. Therefore, business leaders play an important role in achieving the goals of BDA implementation. The understanding of analytics deliverables and effective decisionmaking totally depends on the influencing factors. Several factors such as organizational capability, technology capability, analytics capability, talent or human capability, and the information quality are effecting the

* Corresponding author.

E-mail address: cecilia.upm@gmail.com success of its implementation [8].

Valuing the information systems (IS) investments for BDA implementation and assessing its application will be worthwhile in the organization's effort to develop new big data business model in the future, sustaining competitive advantages and to address new issues and challenges [9]. In the course of assessment during BDA implementation stage, the aim is to determine the relevance and fulfilment of objectives, sustainability of the current business model [10] and business survival for the long term. At this point in time, the assessment of BDA is only at the stage of readiness [11], which focusing only on the big data capabilities and resources. Nonetheless, the assessment of BDA implementation impact is still an understudied research topic. Therefore, the aims of this paper are: 1) to identify and analyze the affecting factors and elements of BDA implementation; and 2) to propose a conceptual model of BDA implementation assessment for effective decision-making.

The organization of this paper will be as follows: the second section focuses on the theoretical background and is followed by the third section that discusses on research methodology. The fourth section presents the discussion and findings of the affecting factors and proposes a conceptual model for BDA implementation assessment while the last section concludes the study by pinpointing the research contribution and suggesting further research work.

\section{THEORETICAL BACKGROUND}

There have been a number of studies that dwelled on developing BDA capabilities models by adopting resource-based view theory (RBV) [12], and the updated version of DeLone and McLean's Information Systems Success Model (ISSM) [13]. Capabilities and resources are the key components of RBV in achieving the organizational performance and sustained competitive advantage [14]. 
In adopting a resource-based perspective, big data researchers have identified various BDA related capabilities and resources that serve as potential grounds of organizational performance. For example, Akter et al., 2016 [7] and Wamba et al., 2017 [15] pointed out that BDA capabilities covers management, talent and technology dimensions that positively influenced the organizational performance. Likewise, empirical findings by Gupta and colleague, 2016 [16] provided evidence on tangible, human skills and intangible resources supported by the BDA capabilities that led to market and operational performance.

Furthermore, the use of business analytics tools has enabled decision making effectiveness in health care through absorptive capability [17]. Several studies have adopted RBV theory to deepen their understanding of BDA capabilities in achieving organizational performance such as, in manufacturing [4] [18], health care [17] [19], retail [15], and non-specific domains [7] [16] [20] [21]. On the other hand, the adoption of ISSM theory focuses only on data, information and system quality factors towards organizational impact and benefits. Thus, system quality and information quality are significant to enhance business value and firm performance in big data surroundings [21].

\section{A. Big Data Analytics Capabilities}

Various concepts have been utilized in the big data literature to describe BDA capabilities. A systematic literature found that the following three concepts were the most commonly used to describe BDA capabilities. The first concept described BDA capability as the most competence to provide business insights using data management, talent (personnel context) and infrastructure (technology context) capability to transform information business into a competitive force [7] [15]. The second concept mainly used the context in health care, where BDA capabilities is regarded as having the ability to acquire, store, process and analyze a large amount of health data in various forms, and deliver meaningful information to users that allow them to discover business values and insights in a timely fashion [2]. The third concept used BDA capability to assemble, integrate, and deploy its big data-based resources in big firms [16]. This study points out the BDA capabilities factors as shown in Table I that includes management capability, organizational capability, technology capability, talent capability (data analytics personnel expertise), information processing capability and other related capabilities.

Table I. Big Data Analytics Capabilities Factors and Variables

\begin{tabular}{|c|c|c|c|}
\hline Factors & & Variables & Sources \\
\hline Management capability & $\begin{array}{l}\text { - Big data analytics planning } \\
\text { - Investment decision-making }\end{array}$ & - Coordination and control & [7] [15] \\
\hline Technology capability & $\begin{array}{l}\text { - Infrastructure flexibility } \\
\text { - Process integration and standardization } \\
\text { - Integration of IT systems }\end{array}$ & $\begin{array}{l}\text { - Effective use of data aggregation tools } \\
\text { - Effective use of data analysis tools } \\
\text { - Effective use of data interpretation tools }\end{array}$ & $\begin{array}{l}{[7][15][22]} \\
{[23][4][5]} \\
{[17]}\end{array}$ \\
\hline Talent capability & $\begin{array}{l}\text { - Technical knowledge } \\
\text { - Technology management capability } \\
\text { - Relational knowledge } \\
\text { - Managerial skills }\end{array}$ & $\begin{array}{l}\text { - Business knowledge } \\
\text { - Analytics capabilities } \\
\text { - People skills } \\
\text { - Training people } \\
\text { - Engaging people }\end{array}$ & $\begin{array}{c}{[7][15][16]} \\
{[23][4][5]}\end{array}$ \\
\hline Information processing capability & $\begin{array}{l}\text { - Analytical capability } \\
\text { - Patterns of care } \\
\text { - Unstructured data analytical capability } \\
\text { - Decision support capability } \\
\text { - Traceability capability } \\
\end{array}$ & $\begin{array}{l}\text { - Speed of decisions } \\
\text { - Predictive analytics } \\
\text { - Interoperability } \\
\text { - Data analytics (data collection, data analysis and } \\
\text { modelling, data visualization, insight generation) }\end{array}$ & $\begin{array}{l}{[18][19]} \\
{[23][2]}\end{array}$ \\
\hline Other capability & - Process-oriented dynamic capabilities & - Absorptive capability & {$[15][17]$} \\
\hline
\end{tabular}

Table II. Intangible and Tangible Resources Factors and Variables

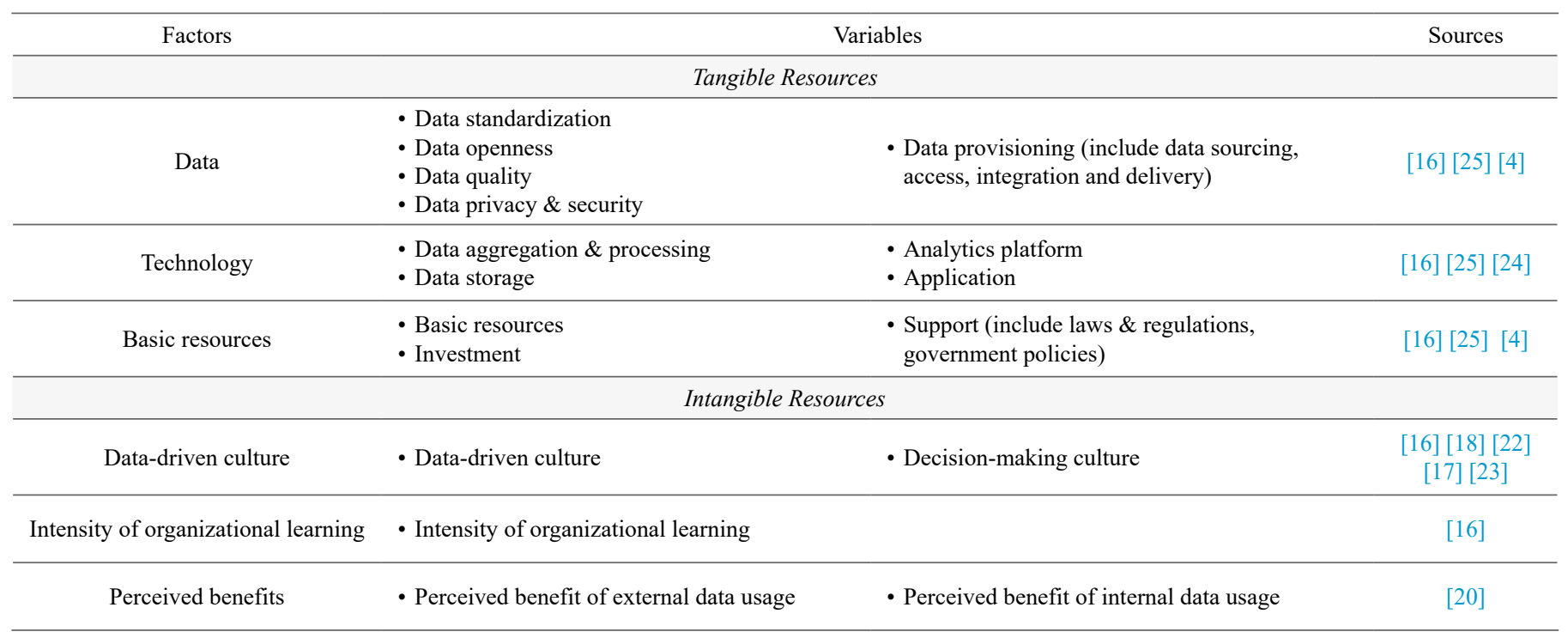




\section{B. Big Data Analytics Resources}

Based on RBV theory, some studies have categorized BDA resources into tangible and intangible resources. Table II listed factors and variables for tangible and intangible resources discussed in BDA studies. The big data analytic capability model developed by Gupta and George (2016) [16] equally relies on tangibles resources such as data, technology, basic resources, and intangibles resources such as datadriven culture and intensity of organizational learning. Furthermore, intangible resources also include perceived benefits of external and internal data usage [20].

\section{Big Data Analytics Quality}

BDA is associated with transforming and analyzing raw data into valuable information as well as knowledge in creating business values. In relation to this, quality of data and information are critical for organizational impact which will facilitate top management in decision-making. Earlier studies have shown that BDA quality factors are consisting of data quality, information quality and system quality as shown in Table III. An empirical study in BDA environment by Ji-fan Ren et al. (2016) [21] identified system quality and information quality is very crucial in enhancing business value and firms' performance.

Table III. Big Data Analytics Quality Factors and Variables

\begin{tabular}{|c|c|c|c|}
\hline Factors & & riables & Sources \\
\hline Data Quality & - Data consistency & - Data completeness & {$[20]$} \\
\hline $\begin{array}{l}\text { Information } \\
\text { Quality }\end{array}$ & $\begin{array}{l}\text { - Completeness } \\
\text { - Currency } \\
\text { - Format }\end{array}$ & $\begin{array}{l}\text { - Accuracy } \\
\text { - Security and integrity }\end{array}$ & {$[5][21]$} \\
\hline $\begin{array}{l}\text { System } \\
\text { Quality }\end{array}$ & $\begin{array}{l}\text { - Reliability } \\
\text { - Adaptability } \\
\text { - Integration }\end{array}$ & $\begin{array}{l}\text { - Accessibility } \\
\text { - System response time } \\
\text { - System privacy }\end{array}$ & {$[21]$} \\
\hline
\end{tabular}

\section{METHODOLOGY}

The development of the conceptual model in assessing the BDA implementation was carried out based on multiple steps as illustrated in Fig. 1. The review processes was based on the systematic literature review (SLR) approach [26][27], and continued with content analysis before the relevant theories were identified. The review exercise has investigated 15 articles on the implementation of BDA in various domains, and categorized them into two types of research analysis namely empirical and case study.

The initial investigation begins by formulating a research question such as 'What are the factors and elements to be considered in developing BDA implementation assessment (BDAIA) model?' Then, the process continues by searching information from electronic journal databases such as scopus, science direct, google scholar and snowballing technique, and then 15 relevant articles were selected. The relevant articles were then analyzed using matrix table (Table IV). This study has listed 4 factors and 15 elements to be considered in developing the assessment model, and the findings are discussed in the following section (Section 4). Finally, the design of the conceptual model for BDAIA with related factors and elements is presented in the conclusion.

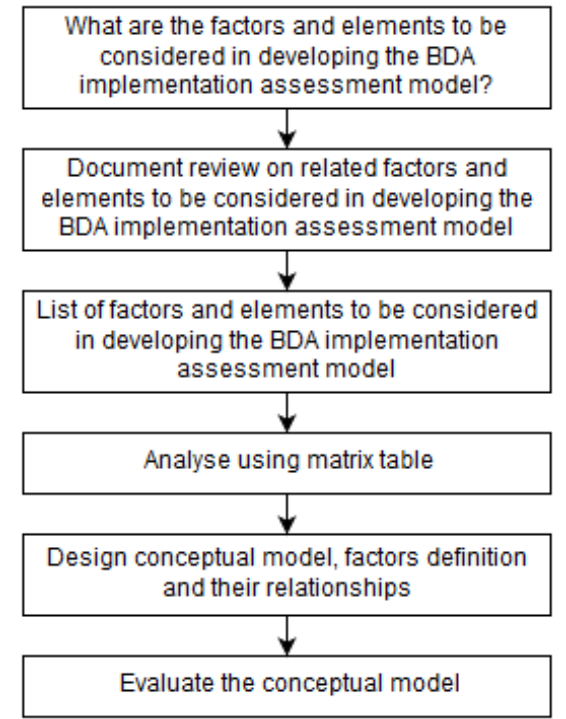

Fig. 1. The process of developing BDAIA conceptual model.

\section{FINDINGS AND DisCUSSION}

Table IV presents the related BDA factors discussed in other studies which includes BDA capabilities, tangible resources, intangible resources and BDA quality, together with their elements that affects BDA implementation. The frequency of each element were shown in Fig. 2. Technology element in both BDA capability and tangible resources, and talent or human element were shown to be the two most frequent elements highlighted in BDA implementation. This is followed by organizational capability, data-driven culture, and information processing capability elements. Subsequently, elements such as data and basic resources were the least discussed in other studies. BDA elements such as management capability, other capability, BDA quality and perceived benefits were the least discussed elements in the empirical studies as they were considered still in their infancy stage in the big data environment.

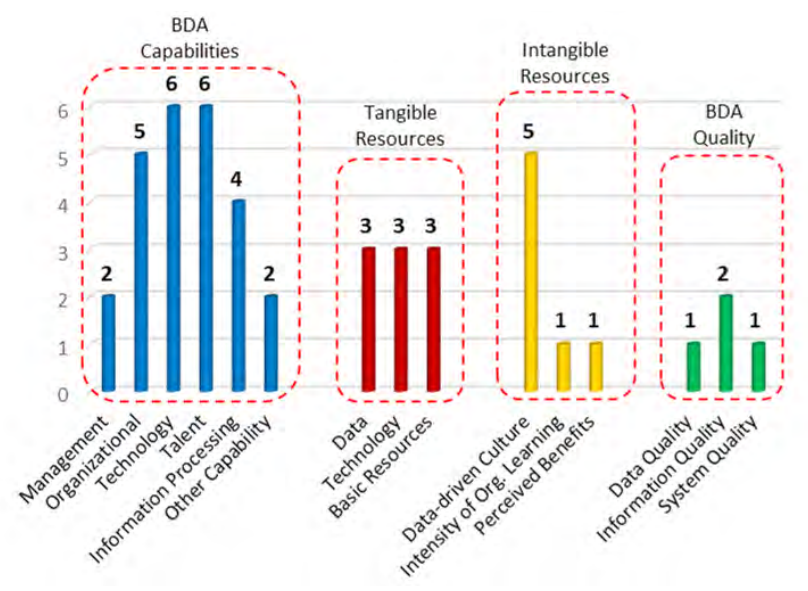

Fig. 2. The frequency of BDA elements.

Drawing on RBV theory and ISSM, big data analytics implementation assessment is conceptualized and being determined by three dimensions: organization, people and technology. Performing data strategy factor is an important criteria in organization dimension. It refers to the organizations' assurance in performing strategic analytics alignment, managerial commitment and resources management. Meanwhile, collaborative knowledge worker factor is determined by the people dimension which refers to the analytics personnel skills, 
Table IV. Factors and Elements Affecting the BDA Implementation

\begin{tabular}{|c|c|c|c|c|c|c|c|c|c|c|c|c|c|c|c|c|}
\hline $\begin{array}{l}\text { Factors/ } \\
\text { Elements }\end{array}$ & 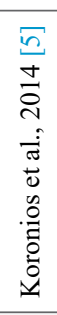 & 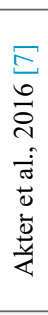 & 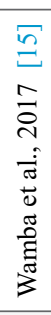 & 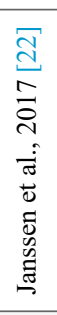 & 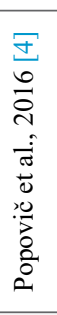 & 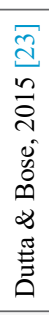 & 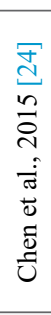 & 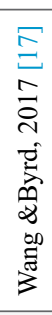 & 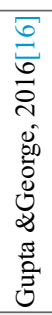 & 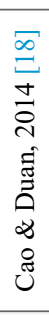 & 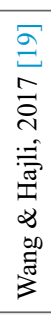 & 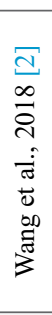 & 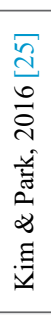 & 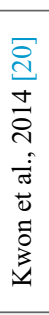 & 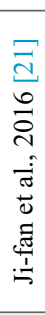 & 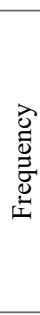 \\
\hline Management & & $\mathrm{X}$ & $\mathrm{X}$ & & & & & & & & & & & & & 2 \\
\hline Organizational & $\mathrm{X}$ & & & $\mathrm{X}$ & $\mathrm{X}$ & $\mathrm{X}$ & $\mathrm{X}$ & & & & & & & & & 5 \\
\hline Technology & $\mathrm{X}$ & $\mathrm{X}$ & $\mathrm{X}$ & $\mathrm{X}$ & & $\mathrm{X}$ & & $\mathrm{X}$ & & & & & & & & 6 \\
\hline Talent/Human & $\mathrm{X}$ & $\mathrm{X}$ & $\mathrm{X}$ & & $\mathrm{X}$ & $\mathrm{X}$ & & & $\mathrm{X}$ & & & & & & & 6 \\
\hline Information Processing & & & & & & $\mathrm{X}$ & & & & $\mathrm{X}$ & $\mathrm{X}$ & $\mathrm{X}$ & & & & 4 \\
\hline Technology & & & & & & & $\mathrm{X}$ & & $\mathrm{X}$ & & & & $\mathrm{X}$ & & & 3 \\
\hline Basic Resources & & & & & $\mathrm{X}$ & & & & $\mathrm{X}$ & & & & $\mathrm{X}$ & & & 3 \\
\hline \multicolumn{17}{|l|}{ Intangible Resources } \\
\hline Data-driven Culture & & & & $\mathrm{X}$ & & $\mathrm{X}$ & & $\mathrm{X}$ & $\mathrm{X}$ & $\mathrm{X}$ & & & & & & 5 \\
\hline Organization Learning & & & & & & & & & $\mathrm{X}$ & & & & & & & 1 \\
\hline Perceived Benefits & & & & & & & & & & & & & & $\mathrm{X}$ & & 1 \\
\hline \multicolumn{17}{|l|}{ BDA Quality } \\
\hline Data Quality & & & & & & & & & & & & & & $\mathrm{X}$ & & 1 \\
\hline
\end{tabular}

Table V. Factors, Elements and Definitions

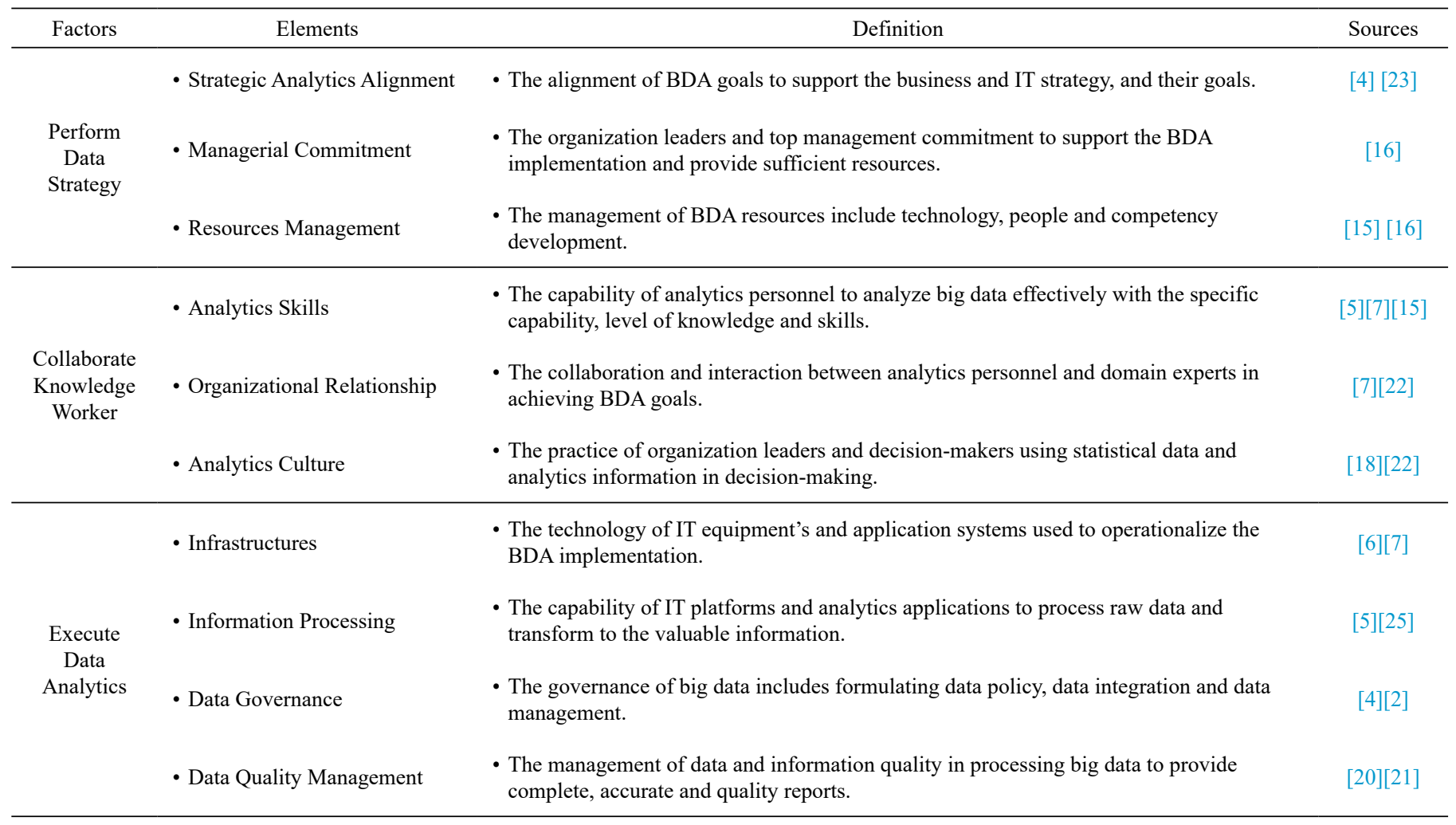




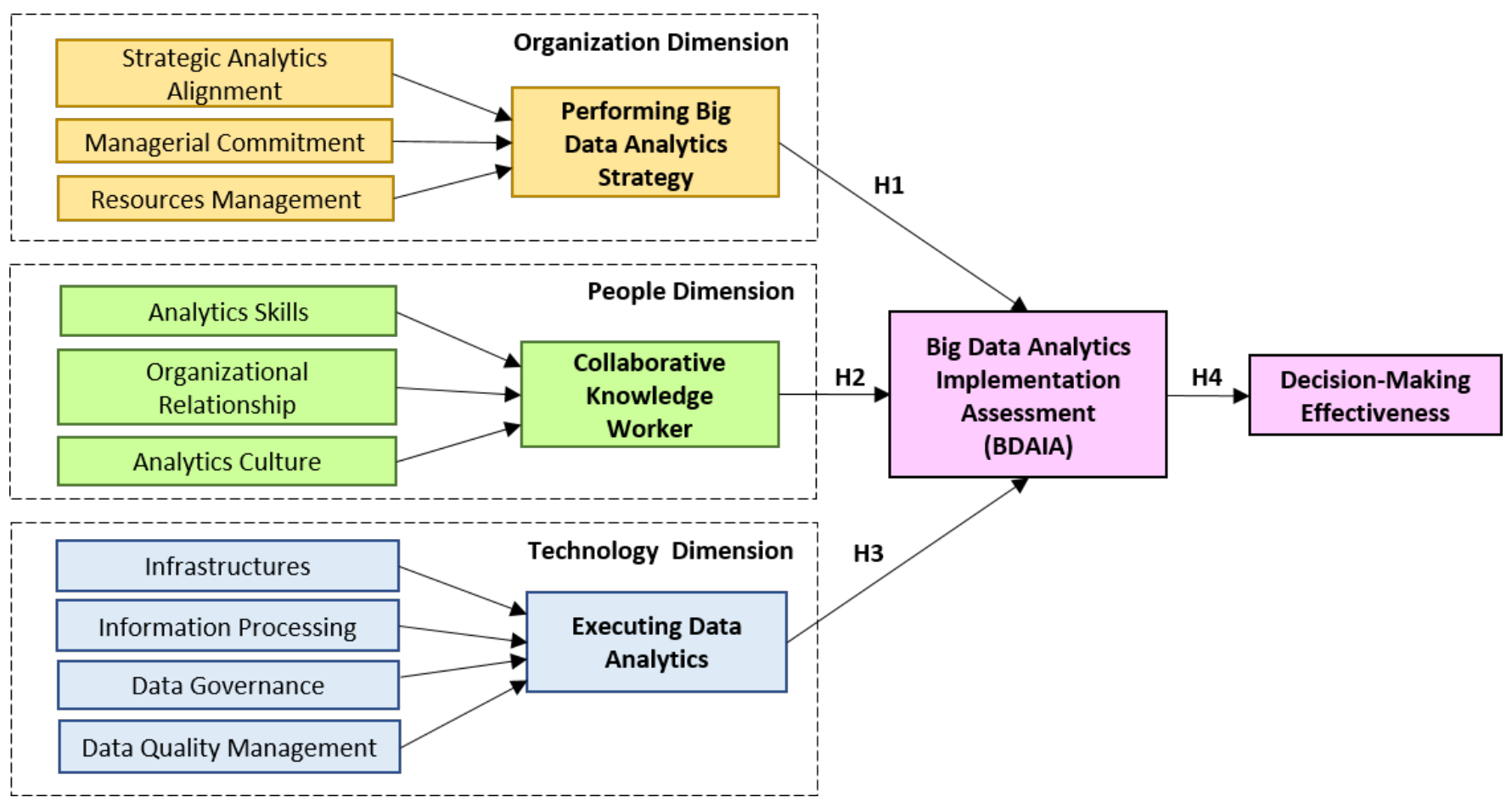

Fig. 3. Conceptual model BDA implementation assessment effect on decision-making.

organizational relationship and analytics culture. Subsequently, in technology dimension, the elements of executing data analytics factor including IT infrastructures, information processing, data governance and data quality management. Table $\mathrm{V}$ presents the factors with related elements and its definition that are crucial for creating the conceptual model.

Fig. 3 illustrated the conceptual model for big data analytics implementation assessment (BDAIA). The effect of BDAIA consequently influences decision-making effectiveness, as well as the indirect effect of performing BDA strategy, collaborative knowledge worker and executing data analytics factors. In this line, the study hypothesis is:

H1: Performing BDA strategy has a significant positive effect on BDAIA

H2: Collaborative knowledge worker has a significant positive effects on BDAIA.

H3: Executing data analytics has a significant positive effect on BDAIA.

H4: BDAIA has positive effects on decision-making effectiveness.

\section{CONCLUSION}

A conceptual model was found the most useful for assessing the big data analytics implementation. The model is capable of measuring the relationship of organization, people and technology dimensions that affect the assessment of BDA implementation and decisionmaking. The follow-up research activity will be developing a survey instrument using questionnaires. The proposed conceptual model and questionnaires will be then to be verified by experts from academics and industry. In relation to this, a pilot study will be conducted and to be followed by the actual study. The model will be validated then using statistical tools, and the results gained will provide an insight for business leaders to plan, sustain and enhance the capability of decisionmaking based on data-driven by assessing the relevant resources.

\section{REFERENCES}

[1] R. Sharma, S. Mithas, and A. Kankanhalli, "Transforming DecisionMaking Processes: A Research Agenda for Understanding the Impact of Business Analytics on Organisations," European Journal of Information Systems, vol. 23, no. 4, pp. 433-441 (2014).

[2] Y. Wang, L. Kung, and T. A. Byrd, "Big Data Analytics: Understanding Its Capabilities and Potential Benefits for Healthcare Organizations," Technological Forecasting and Social Change, vol. 126, pp. 3-13 (2018).

[3] Y. Wang, L. Kung, W. Y. C. Wang, and C. G. Cegielski, "An Integrated Big Data Analytics-enabled Transformation Model: Application to Health Care," Information and Management, vol. 55, pp. 64-79 (2018).

[4] A. Popovič, R. Hackney, R. Tassabehji, and M. Castelli, "The Impact of Big Data Analytics on Firms' High Value Business Performance," Information Systems Frontiers, pp. 1-14 (2016).

[5] A. Koronios, J. Gao, and S. Selle, "Big Data Project Success - A Meta Analysis," in 18th Pacific Asia Conference on Information Systems, PACIS Proceedings, pp. 376-390 (2014).

[6] S. Fosso Wamba, S. Akter, A. Edwards, G. Chopin, and D. Gnanzou, "How 'big data' can make big impact: Findings from A Systematic Review and A Longitudinal Case Study," International Journal of Production Economics, vol. 165, pp. 234-246 (2015).

[7] S. Akter, S. F. Wamba, A. Gunasekaran, R. Dubey, and S. J. Childe, "How to improve firm performance using big data analytics capability and business strategy alignment?," International Journal of Production Economics, vol. 182, pp. 113-131 (2016).

[8] C. Adrian, Rusli Abdullah, R. Atan, and Yusmadi Yah Jusoh, "Factors Influencing to the Implementation Success of Big Data Analytics : A Systematic Literature Review," in 2017 International Conference on Research and Innovation in Information Systems (ICRIIS), pp. 1-6 (2017).

[9] S. Lavalle, E. Lesser, R. Shockley, M. S. Hopkins, and N. Kruschwitz, "Big Data, Analytics and the Path from Insights to Value," MIT Sloan Management Review, vol. 52, no. 2, pp. 21-34 (2011).

[10] A. Abbasi, S. Sarker, and R. Chiang, "Big Data Research in Information Systems: Toward an Inclusive Research Agenda," Journal of the Association for Information Systems, vol. 17, no. 2 (2016).

[11] M. Mach-Król, "A Survey and Assessment of Maturity Models for Big Data Adoption," in 11th International Conference on Strategic Management and Its Support by Information Systems (SMSIS), pp. 391-399 (2015).

[12] M. Wade and J. Hulland, "Review: The Resource-Based View and 
Information Systems Research: Review, Extension, and Suggestions for Future Research," MIS Quarterly, vol. 28, no. 1, pp. 107-142 (2004).

[13] W. H. Delone and E. R. Mclean, "The DeLone and McLean Model of Information Systems Success: A Ten-Year Update," Journal of Management Information Systems, vol. 19, no. 4, pp. 9-30 (2003).

[14] J. B. Barney, "Firm Resources and Sustained Competitive Advantage," Journal of Management, vol. 17, no. 1, pp. 99-120 (1991).

[15] S. F. Wamba, A. Gunasekaran, S. Akter, S. J. Ren, R. Dubey, and S. J. Childe, "Big Data Analytics and Firm Performance: Effects of Dynamic Capabilities," Journal of Business Research, vol. 70, pp. 356-365 (2017).

[16] M. Gupta and J. F. George, "Toward the Development of a Big Data Analytics Capability," Information and Management, vol. 53, no. 8, pp. 1046-1064 (2016)

[17] Y. Wang and T. Byrd, "Business Analytics-Enabled Decision Making Effectiveness through Knowledge Absorptive Capacity in Health Care," Journal of Knowledge Management, vol. 21, no. 3, pp. 517-539 (2017).

[18] G. Cao and Y. Duan, "Gaining Competitive Advantage from Analytics through the Mediation of Decision-Making Effectiveness : An Empirical Study of UK Manufacturing Companies," in PACIS Proceedings, p. 377 (2014).

[19] Y. Wang and N. Hajli, "Exploring the Path to Big Data Analytics Success in Healthcare," Journal of Business Research, vol. 70, pp. 287-299 (2017).

[20] O. Kwon, N. Lee, and B. Shin, "Data Quality Management, Data Usage Experience and Acquisition Intention of Big Data Analytics," International Journal of Information Management, vol. 34, pp. 387-394 (2014).

[21] S. Ji-fan Ren, S. Fosso Wamba, S. Akter, R. Dubey, and S. J. Childe, "Modelling Quality Dynamics, Business Value and Firm Performance in a Big Data Analytics Environment," International Journal of Production Research, pp. 1-16 (2016).

[22] M. Janssen, H. Van Der Voort, and A. Wahyudi, "Factors Influencing Big Data Decision-Making Quality," Journal of Business Research, vol. 70, pp. 338-345 (2017).

[23] D. Dutta and I. Bose, "Managing a Big Data project: The case of Ramco Cements Limited," International Journal of Production Economics, vol. 165, pp. 293-306 (2015).

[24] D. Q. Chen, D. S. Preston, and M. Swink, "How the Use of Big Data Analytics Affects Value Creation in Supply Chain Management," Journal of Management Information Systems, vol. 32, no. 4, pp. 4-39 (2015).

[25] M.-K. Kim and J.-H. Park, "Identifying and Prioritizing Critical Factors for promoting the Implementation and Usage of Big Data in Healthcare," Information Development, pp. 1-13 (2016).

[26] B. Kitchenham and S. Charters, "Guidelines for performing Systematic Literature Reviews in Software Engineering," EBSE-2007-01 Technical Report (2007).

[27] C. Okoli and K. Schabram, "A Guide to Conducting a Systematic Literature Review of Information Systems Research," Sprouts: Working Papers on Information Systems, vol. 10(26), pp. 1-51 (2010).

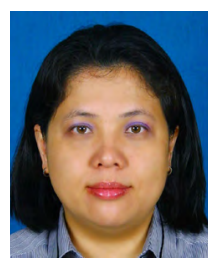

\section{Cecilia Adrian}

Cecilia Adrian is $\mathrm{PhD}$ candidate in the Department of Software Engineering and Information Systems at Universiti Putra Malaysia. She has received Bachelor Engineering in Electronics Computer (1999) from Universiti Putra Malaysia and Master of Science in Computer Security and Resilience (2008) from Newcastle University, United Kingdom. Her interests lie in Information Systems and Big Data Analytics implementation.

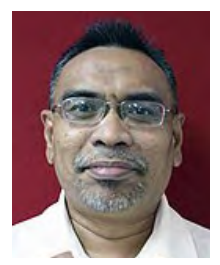

Rusli Abdullah

Rusli Abdullah is currently a Professor and Leader of Applied Informatics Research Group (AIRG) in the Department of Software Engineering and Information Systems, Universiti Putra Malaysia. He holds a PhD from Universiti Teknologi Malaysia (2005), Master of Science in Computer Science (1996) and Bachelor in Computer Science (1988) from Universiti Putra Malaysia. He is also an active member of Association for Information Systems (AIS). His major research interests lie in Knowledge Management and Information Systems. He has authored and co-authored over 80 journals and 63 prestigious conferences.

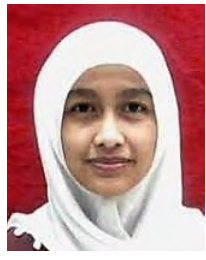

\section{Rodziah Atan}

Rodziah Atan is currently Associate Professor in Faculty of Computer Science and Information Technology, and as Head for Halal Management and Policy Laboratory at Universiti Putra Malaysia. She obtained her $\mathrm{PhD}$ in Software Engineering from Universiti Putra Malaysia in 2006. She specializes in the area of Software Engineering, Software Process Modelling and Cloud Computing Services. She also has published academic books, chapter in books, more than 100 journal publications and conference papers.

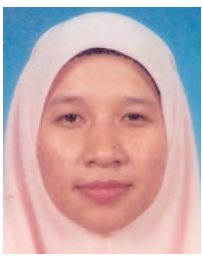

\section{Yusmadi Yah Jusoh}

Yusmadi Yah Jusoh is a senior lecturer at Faculty of Computer Science and Information Technology, Universiti Putra Malaysia. She holds PhD in Information Technology (2008) and Master in Information Technology (1998) from National University of Malaysia. She obtained Bachelor of Economic, major in Economic Analysis and Public Policy (1997) from National University of Malaysia. Her research interests include Management Information System, Information Systems, Information Technology Strategic Planning, and Software Project Management. 